\title{
TAVI in a Patient with Single Coronary Artery: The Choice of Self-Expandable Valve may be Reasonable
}

\author{
Hüseyin Dursun ${ }^{1}$, Jale Zeynep Gönençer ${ }^{1}$, Özalp Karabay², Abidin Cenk Erdal², Dayimi Kaya ${ }^{1}$ \\ ${ }^{1}$ Department of Cardiology, Dokuz Eylül University School of Medicine, İzmir, Turkey \\ ${ }^{2}$ Department of Cardiovascular Surgery, Dokuz Eylül University School of Medicine, İzmir, Turkey
}

Background: Single coronary artery is a rare congenital coronary artery anomaly with the incidence of approximately $0.03 \%-0.05 \%$. Its coexistence with severe aortic stenosis (AS) is even rarer. Patients who undergo transcatheter aortic valve implantation (TAVI) have a risk of coronary obstruction $(1 \%)$ which will be more lethal when the origin of the coronary artery is single.

Case Report: An 81 year-old female was referred to our institution for severe AS. Her coronary angiography revealed a single coronary artery originating from right sinus of valsalva. Since the patient had a high risk for aortic valve surgery, the cardiac team decided to perform transfemoral TAVI with a self-expandable valve.
Conclusion: We presented a successful case of TAVI with Medtronic CoreValve (Medtronic; Minnesota, USA) in a patient with single coronary artery after discussing the base of our strategy for preferring self-expandable valve. To the best of our knowledge, this is the second case of CoreValve implantation in such a patient in the literature. We suggest that the self-expandable valve may be the first choice in these patients because of its recapturable design.

Keywords: Coronary obstruction, self-expandable valve, single coronary artery, transcatheter aortic valve implantation
The coexistence of single coronary artery with severe aortic stenosis (AS) is extremely rare (1-3). The possible complication of coronary obstruction will highly be lethal during transcatheter aortic valve implantation (TAVI) when the origin of the coronary artery is single (4). We present a patient with a single coronary artery from right sinus of valsalva who underwent successful TAVI with Medtronic CoreValve (Medtronic; Minnesota, USA). To the best of our knowledge, this is the second case of TAVI with a self-expandable bioprosthesis.

\section{CASE PRESENTATION}

An 81 year-old female with New York Heart Association Class III dyspnea was referred to our institution with severe
AS. Her past medical history revealed hypertension and chronic renal failure (glomerular filtration rate, $32 \mathrm{~mL} / \mathrm{min}$ ). Transthoracic echocardiography showed an aortic valve area of $0.70 \mathrm{~cm}^{2}$ with a mean gradient of $44 \mathrm{mmHg}$ and preserved left ventricular systolic function. Coronary angiography revealed a single coronary artery arising from the right sinus of valsalva bifurcating into right coronary artery (RCA) within a normal path, left anterior descending artery from conal branch of RCA, and left coronary artery (LCA) giving circumflex and diagonal branches (Figure 1). There was no coronary or peripheral artery stenosis. Since the logistic EuroSCORE and STS scores were $25.9 \%$ and $4.4 \%$, respectively, TAVI with the transfemoral approach was selected by the cardiac team. Multi-slice computerized tomography (CT) confirmed angiographic findings with a proximal course of LCA, aortic an-

This study was presented at $30^{\text {th }}$ Turkish Cardiology Congress with International Participation, 23-26 October 2014, Antalya, Turkey.

Address for Correspondence: Dr. Hüseyin Dursun, Department of Cardiology, Dokuz Eylül University School of Medicine, İzmir, Turkey

Phone: +90 $5057192150 \quad$ e-mail: drhuseyindursun@gmail.com

Received: 5 May $2015 \quad$ Accepted: 28 June 2015 - DOI: $10.5152 /$ balkanmedj.2016.150601

Available at www.balkanmedicaljournal.org 


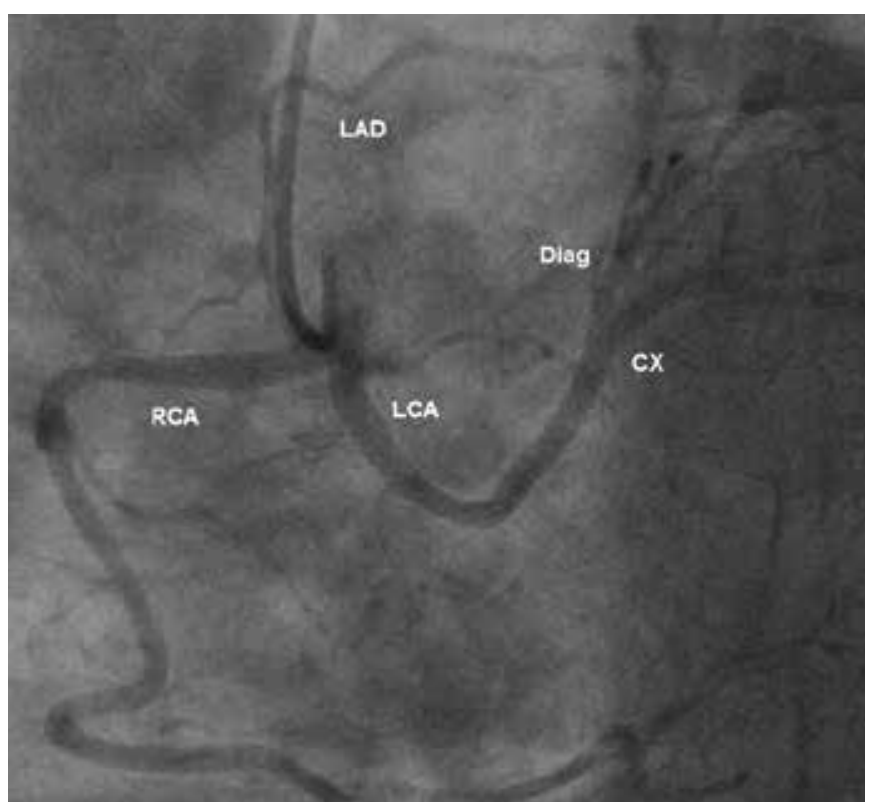

FIG. 1. Coronary angiography of the patient showing single coronary artery originating from right sinus of valsalva

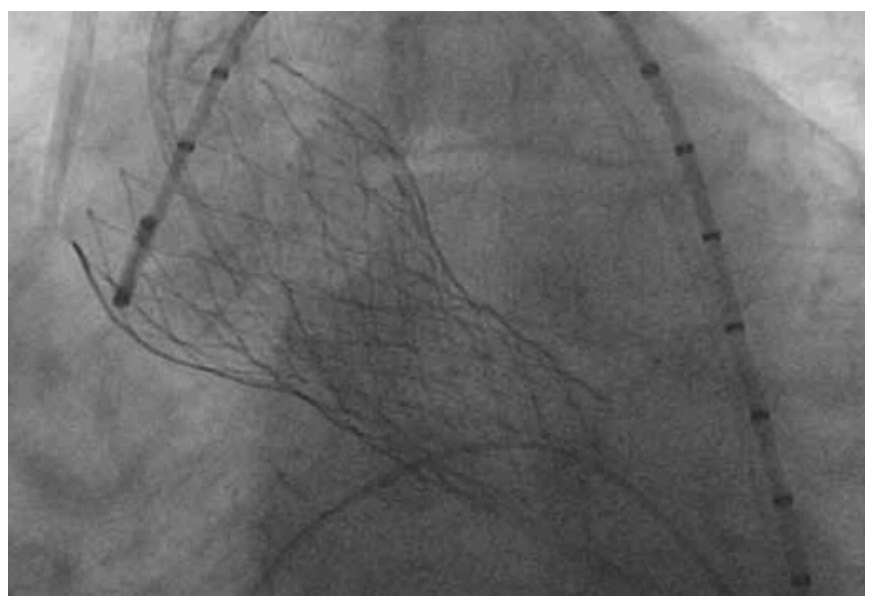

FIG. 2. Fluoroscopic image after CoreValve bioprosthesis deployment

nulus diameter of $22 \mathrm{~mm}$ and distance between aortic annulus and coronary ostium of $11.5 \mathrm{~mm}$. The aortic root was not severely calcified and there were no bulky calcified leaflets close to the coronary ostium.

The cardiac team chose to implant a $26 \mathrm{~mm}$ Medtronic CoreValve with the thought of recapturable design of this bioprosthesis which provides more options to the operator in the case of coronary obstruction. During the procedure, the aortic valve was predilated with a $20 \mathrm{~mm}$ diameter balloon. No significant displacement of calcified leaflets was observed and the patient was hemodynamically stable. A pigtail catheter was then placed in the non-coronary sinus as a visual reference marker for all steps of the valve implantation. Firstly, the lower third of the CoreValve was opened carefully and then

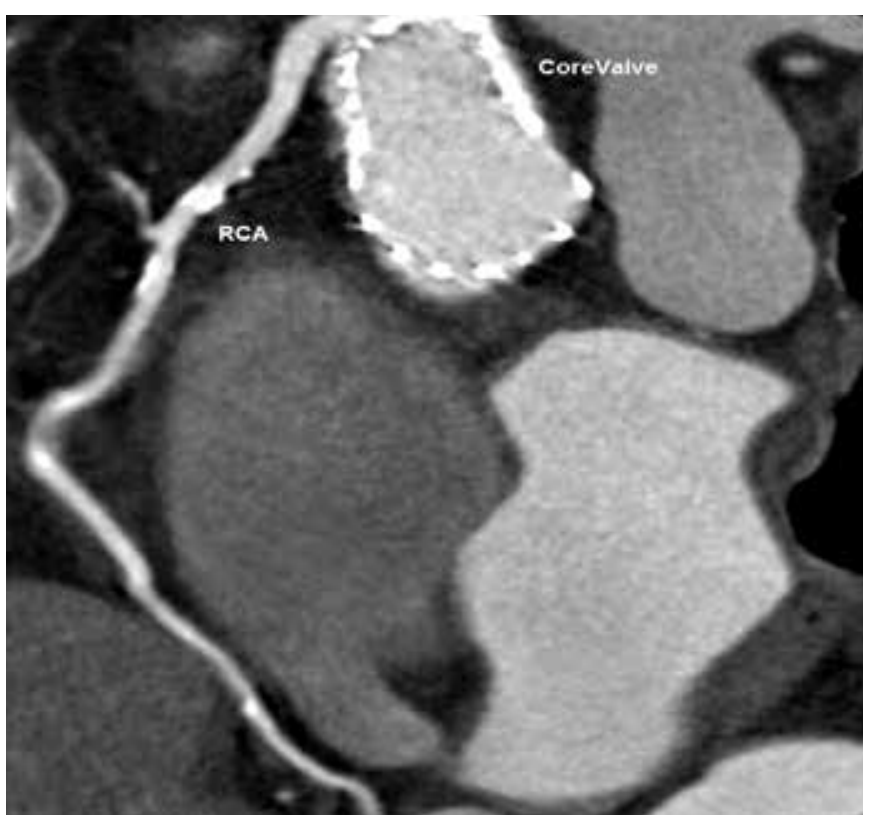

FIG. 3. Post-TAVI multi-slice computed tomography of the patient demonstrating bioprosthesis without any interference with coronary ostium and coronary flow

the other two thirds were deployed. Each step was followed by an aortography showing intact coronary flow and the correct positioning of the valve. There was no need to recapture the valve; thus, we opened the remaining upper thirds of the valve. After full deployment and release of the prosthesis, both the fluoroscopic and hemodynamic images were perfect with no residual aortic regurgitation (Figure 2). Post-procedural multislice CT demonstrated bioprosthetic valve in correct position and intact coronary artery flow (Figure 3 ). The patient was asymptomatic at her 6 months follow-up.

\section{DISCUSSION}

Coronary obstruction during TAVI occurs more frequently in women with no prior coronary artery bypass graft and in whom a balloon-expandable valve was implanted $(5,6)$. The main risk factors are bulky calcifications, low origin of coronary arteries, small sinus of Valsalva and valve misplacement or coronary emboli $(7,8)$. Almost all of the patients with this complication had severe hypotension immediately after the balloon valvuloplasty or bioprosthesis implantation.

There have been 3 cases of successful TAVI procedures, 2 with Edwards SAPIEN XT (Edwards Lifesciences, California, USA) and 1 with CoreValve, in patients with single coronary artery that were all originated from right sinus of valsalva. Sorbets et al. (7) performed two of these cases; one with Edwards Sapien XT, and the other with the Medtronic 
CoreValve. They performed angiography during balloon valvuloplasty to anticipate the risk of coronary obstruction with the balloon-annulus ratio close to 1 . In the third case, Giri et al. (9) implanted the Edwards SAPIEN XT and placed a coronary wire in the LCA to serve as protection for the left main coronary artery during balloon valvuloplasty and bioprosthesis implantation.

In our case, we did not perform any protective intervention during TAVI. We closely followed-up the hemodynamic measurements and performed aortography in each step of valve deployment for the patency of coronary flow with proper valve positioning. Since there are only 3 preceding cases, no consensus exists on the use of certain bioprostheses. Sorbets et al. (7) reported that each bioprosthetic valve does not appear particularly advantageous over the other in the case of a single coronary artery. However, in our opinion, the selfexpandable valve may be advantageous over the balloon-expandable valve because in the case of any complication, such as coronary obstruction by calcified material or metal struts of the bioprosthesis, Medtronic CoreValve can be recaptured until $2 / 3$ of the bioprosthesis is implanted. Next generation self-expandable valves will probably be more advantageous since they have the ability to be recaptured until $80 \%$ of the deployment.

In Conclusion, TAVI with CoreValve is feasible and safe in patients with a single coronary artery and severe AS. The selfexpandable valve may be the first choice, especially because of the recapturable property of the valve.

\section{Ethics Committee Approval: N/A.}

Informed Consent: Written informed consent was obtained from patient who participated in this case.

Peer-review: Externally peer-reviewed.

Author contributions: Concept - H.D., A.C.E., D.K.; Design H.D., D.K.; Supervision - H.D., J.Z.G., Ö.K.; Resource - A.C.E., Ö.K., J.Z.G.; Materials - H.D., D.K.; Data Collection and/or Processing - H.D., J.Z.G, Ö.K.; Analysis and/or Interpretation - H.D., Ö.K., A.C.E, D.K.; Literature Search - H.D., J.Z.G., A.C.E.; Writing - H.D., J.Z.G., D.K.; Critical Reviews - H.D., J.Z.G., Ö.K., A.C.E., D.K.
Acknowledgements: Authors would like to thank to Mustafa Barış, MD for his work on computerized tomography views.

Conflict of Interest: Professor Kaya is a clinical proctor for Medtronic Inc., and Edwards Lifesciences.

Financial Disclosure: The authors declared that this study has received no financial support.

\section{REFERENCES}

1. Desmet W, Vanhaecke J, Vrolix M, Van de Werf F, Piessens $\mathrm{J}$, Willems $\mathrm{J}$, et al. Isolated single coronary artery: a review of 50,000 consecutive coronary angiographies. Eur Heart $J$ 1992;13:1637-40.

2. Boissier F, Coolen N, Nataf P, Tchetche D. Sudden death related to an anomalous origin of the right coronary artery. Ann Thorac Surg 2008;85:1077-9. [CrossRef]

3. Corbett M, Powers J, King S, Quinn M, Harris D. Single coronary artery. J Am Coll Cardiol 2009;53:455. [CrossRef]

4. Stajic Z, Mijailovic Z. Single coronary artery associated with severe bicuspid aortic valve stenosis. J Saudi Heart Assoc 2013;25:277-8. [CrossRef]

5. Ribeiro HB, Nombela-Franco L, Urena M, Mok M, Pasian S, Doyle D, et al. Coronary obstruction following transcatheter aortic valve implantation: a systematic review. JACC Cardiovasc Interv 2013;6:452-61. [CrossRef]

6. Khatri PJ, Webb JG, Rodes-Cabau J, Fremes SE, Ruel M, Lau $\mathrm{K}$, et al. Adverse effects associated with transcatheter aortic valve implantation: a meta-analysis of contemporary studies. Ann Intern Med 2013;158:35-46. [CrossRef]

7. Sorbets E, Choby M, Tchetche D. Transcatheter aortic valve implantation with either CoreValve or SAPIEN XT devices in patients with a single coronary artery. I Invasive Cardiol 2012;24:342-4.

8. Stabile E, Sorropago G, Cioppa A, Cota L, Agrusta M, Lucchetti $\mathrm{V}$, et al. Acute left main obstructions following TAVI. EuroIntervention 2010;6:100-5. [CrossRef]

9. Giri J, Szeto WY, Bavaria J, Herrmann HC. Transcatheter aortic valve replacement with coronary artery protection performed in a patient with an anomalous left main coronary artery. $J$ Am Coll Cardiol 2012;7:60. [CrossRef] 